\title{
Impact of Myocardial Revascularization Method on Smoking Cessation: Coronary Artery Bypass Grafting versus Percutaneous Coronary Intervention
}

Ricardo das Neves', MD; Greicy Kelly Avila², MD; Fernando de Barros Oliveira'1, MD; João Augusto Ferraz de Sampaio', MD

\section{Abstract}

Introduction: Smoking is a serious public health issue, being a precursor of heart disease and a predictor of sudden death due to myocardial ischemia. Major events in the patient's health can lead to radical changes in habits and the choice for different myocardial revascularization methods might differently impact smoking cessation and relapse.

Objective: To study the rate and perpetuation of smoking cessation after myocardial revascularization comparing coronary artery bypass grafting (CABG) and percutaneous coronary intervention (PCI).

Methods: Smokers submitted to myocardial revascularization were divided into CABG and $\mathrm{PCl}$ groups. The research was conducted through interviews at the Hospital Santa Lucinda outpatient clinic. Patients with smoking cessation longer than 90 days before hospital admission, combined procedures, hospital readmission before $\mathbf{3 6 0}$ days after discharge, cases of death at any time, and emergency procedures were excluded from the study. The start of the smoking cessation period was determined as just after hospital discharge, with a follow-up of 12 months.

Results: The proportion of patients reporting smoking relapse was significantly lower in the CABG than in the PCl group at $30(11.1 \%$ vs. $20.8 \% ; P=0.039)$ and at 180 days ( $23.1 \%$ vs. $41.5 \% ; P=0.002)$, but no differences were observed between the two groups at 360 days after hospital discharge (51.9\% vs. $54.1 \% ; P=0.719)$. High levels of nicotine dependence and passive smoking showed to be important predictors of smoking relapse in the long-term.

Conclusion: The occurrence of a major surgical procedure seems to have beneficial psychological effects, representing an interesting setting for smoking cessation counseling to have higher chances of success.

Keywords: Myocardial Infarction. Myocardial Revascularization. Angioplasty, Balloon, Coronary. Angioplasty. Smoking. Tobacco Use Cessation.

\begin{tabular}{ll}
\hline Abbreviations, acronyms \& symbols \\
\hline CABG $\quad=$ Coronary artery bypass grafting \\
CRP $\quad=$ C-reactive protein \\
INCA = Instituto Nacional de Câncer \\
PCI = Percutaneous coronary intervention \\
\hline
\end{tabular}

\section{INTRODUCTION}

Smoking is a serious public health issue, being a precursor of heart disease and a predictor of sudden death due to myocardial ischemia ${ }^{[1]}$. According to the Instituto Nacional de Câncer (INCA), passive smokers present a 24\% higher risk of myocardial infarction compared to control patients ${ }^{[2]}$. Smoking is

'Cardiovascular Surgery Department of Hospital Santa Lucinda, Sorocaba, São Paulo, Brazil.

${ }^{2}$ Hospital Unimed, Salto, São Paulo, Brazil.

This study was carried out at the Hospital Santa Lucinda, Sorocaba, São Paulo, Brazil.

No financial support. No conflict of interest. an of the most important public health problems characteristic only of the human species. The World Health Organization says that smoking should be considered a pandemic, as around five million people die each year as a result of tobacco-related diseases. Of the total deaths occurred, four million are in the male sex and one million in the female sex. In the year 2025, there will be 10 million deaths from tobacco use if there is no change in the current prevalence of smoking. Cigarette kills more than the sum of other preventable causes of death such as cocaine, heroin, alcohol, fires, suicides and AIDS in developed countries ${ }^{[3]}$.

Smoking cessation is one of the main interventions during the treatment of ischemic coronary disease. Smoking cessation, alone, results in a reduction of approximately $36 \%$ in the risk of death and $32 \%$ in the risk of non-fatal myocardial infarction ${ }^{[4]}$. The success in quitting cigarette addiction, however, is limited, with success rates varying from $10 \%$ to $25 \%$ after one year of smoking

Correspondence Address:

Ricardo das Neves

Alameda das Dálias, 370 - Jardim Simus - Sorocaba, SP, Brazil Zip code: 18055-195

E-mail: ricardoneves@hotmail.com.br 
cessation ${ }^{[5]}$. According to the literature, coronary artery bypass grafting $(C A B G)$ is an important motivation factor for smoking cessation ${ }^{[6]}$.

Considering the hypothesis that there is a strong association between a major event in the patient's health and a radical change in habit, the aim of the present study was to investigate the rate and perpetuation of smoking cessation after two different myocardial revascularization methods, comparing the findings of $C A B G$ and percutaneous coronary intervention ( $\mathrm{PCl})$.

\section{METHODS}

This cross-sectional study was based on data collected at Santa Lucinda Hospital, in the city of Sorocaba, Brazil. A total of 199 patients underwent CABG surgery and 768 patients underwent $\mathrm{PCl}$, between January 2014 and August 2015. The inclusion criterion was smoking, independent of the time of addiction, being excluded patients with smoking cessation for more than 90 days prior to hospital admission, with combined approach with angioplasty followed by revascularization during hospitalization, death and rehospitalization in the selected period. After the selection of patients, the study has 108 patients who underwent CABG and 159 patients who underwent $\mathrm{PCl}$, who were interviewed and submitted to a questionnaire about nicotine addiction through the Fagerström test, smoking cessation conditions with 30, 180 and 360 days after hospital discharge, cohabitation with other smokers, schooling, comorbidities, age, sex, and median income. When complementation data was helpful, patients were approached by telephone contact.
Patients were divided into two groups according to the type of revascularization procedure performed: $\mathrm{PCl}$ or CABG. Nicotine dependence was classified according to score on Fagerström test as very low to medium (1 to 5 points) or high to very high (6 or more points). Age was categorized as $\leq 60$ or $>60$ years old. Monthly income was recorded as a function of the Brazilian minimum wage (R\$937.00 (US\$287.89) in January $1^{\text {st }}$ 2017). Patients living with smokers were considered to be exposed to passive smoking. The main outcome of the study was relapse of smoking and determined only by a single cigarette consumed again.

Data regarding all factors assessed was described for each group (Table 1). Number of people relapsing to smoking was summarized in absolute numbers and cumulative percentages (Table 2). Differences between the groups evaluated were assessed with chi-square tests for categorical data and with t-tests for continuous data. The occurrence of smoking relapse was presented with Kaplan-Meier survival curves, and differences in smoking relapse rates between $\mathrm{PCl}$ and $\mathrm{CABG}$ groups were evaluated with a log-rank test.

Logistic regression models were applied for identifying factors associated with smoking relapse at each time point of the study: 30, 180 and 360 days. Initially the association between the assessed factors and smoking cessation was assessed in univariate models (Table 3). Subsequently, all factors associated with smoking cessation with a $P$-value $<0.250$ on the univariate models were included in multivariate models. Stepwise backward elimination was applied for selection of the best fitting model. The final model was restricted to variables with $P$-values $<0.05$ in the multivariate analyses (Table 4). Interaction between the evaluated factors was

Table 1. Descriptive analysis of patients undergoing surgical revascularization (CABG) or percutaneous intervention (PCI).

\begin{tabular}{|c|c|c|c|c|}
\hline & & CABG & $\mathrm{PCl}$ & $P$-value \\
\hline \multirow{3}{*}{ Age } & Mean and standard deviation (years) & $61.8 \pm 8.8$ & $65.5 \pm 10.1$ & 0.02 \\
\hline & Up to 60 years & $44(40.7 \%)$ & $53(33.3 \%)$ & 0.217 \\
\hline & Over 60 years & $64(59.3 \%)$ & $106(66.7 \%)$ & \\
\hline \multirow{2}{*}{ Sex } & Male & $83(76.9 \%)$ & $98(61.6 \%)$ & 0.009 \\
\hline & Female & $25(23.1 \%)$ & $61(38.4 \%)$ & \\
\hline \multicolumn{2}{|c|}{ Systemic arterial hypertension } & $60(55.6 \%)$ & 69 (43.4\%) & 0.051 \\
\hline \multicolumn{2}{|l|}{ Diabetes mellitus } & $24(22.2 \%)$ & $47(29.6 \%)$ & 0.183 \\
\hline \multirow{2}{*}{ Fagerström test } & Very low to medium & $83(76.9 \%)$ & $115(72.3 \%)$ & 0.407 \\
\hline & High to very high & $25(23.1 \%)$ & $44(27.7 \%)$ & \\
\hline \multicolumn{2}{|l|}{ Passive smoking } & $12(11.1 \%)$ & $28(17.6 \%)$ & 0.144 \\
\hline \multirow{3}{*}{ Education } & Middle school & $69(63.9 \%)$ & $114(71.7 \%)$ & 0.393 \\
\hline & High school & $26(24.1 \%)$ & $31(19.5 \%)$ & \\
\hline & Higher education & $13(12.0 \%)$ & $14(8.8 \%)$ & \\
\hline \multirow{3}{*}{ Average income } & 1-2 minimum wages & $59(54.6 \%)$ & $97(61.0 \%)$ & 0.520 \\
\hline & 2-3 minimum wages & $36(33.3 \%)$ & $43(27.0 \%)$ & \\
\hline & $>3$ minimum wages & $13(12.0 \%)$ & 19 (11.9\%) & \\
\hline
\end{tabular}

$\mathrm{CABG}=$ coronary artery bypass grafting; $\mathrm{PCl}=$ percutaneous coronary intervention 
Table 2. Relapse to smoking in patients undergoing surgical revascularization (CABG) or percutaneous intervention ( $\mathrm{PCl}$ ).

\begin{tabular}{l|c|c|c}
\hline & CABG & PCI & $\boldsymbol{P}$-value \\
\hline 30 days & $12(11.1 \%)$ & $33(20.8 \%)$ & 0.039 \\
\hline 180 days & $25(23.1 \%)$ & $66(41.5 \%)$ & 0.002 \\
\hline 60 days & $56(51.9 \%)$ & $86(54.1 \%)$ & 0.719 \\
\hline
\end{tabular}

$\mathrm{CABG}=$ coronary artery bypass grafting; $\mathrm{PCl}=$ percutaneous coronary intervention

Table 3. Univariate logistic regression model.

\begin{tabular}{|c|c|c|c|c|c|c|c|c|c|c|}
\hline & & \multicolumn{3}{|c|}{30 days } & \multicolumn{3}{|c|}{180 days } & \multicolumn{3}{|c|}{360 days } \\
\hline & & OR & $95 \% \mathrm{Cl}$ & $P$ & OR & $95 \% \mathrm{Cl}$ & $P$ & OR & $95 \% \mathrm{Cl}$ & $P$ \\
\hline \multirow{2}{*}{ Procedure } & CABG & 1.00 & - & - & 1.00 & - & - & 1.00 & - & - \\
\hline & $\mathrm{PCl}$ & 2.10 & $1.03-4.27$ & 0.042 & 2.36 & $1.36-4.07$ & 0.002 & 1.09 & $0.67-1.79$ & 0.719 \\
\hline \multirow{2}{*}{ Age } & Up to 60 years & 1.00 & - & - & 1.00 & - & - & 1.00 & - & - \\
\hline & Over 60 years & 5.66 & $2.15-14.89$ & $<0.001$ & 1.16 & 0.68-1.97 & 0.580 & 1.26 & $0.77-2.08$ & 0.361 \\
\hline \multirow{2}{*}{ Sex } & Male & 1.00 & - & - & 1.00 & - & - & 1.00 & - & - \\
\hline & Female & 1.35 & $0.69-2.62$ & 0.382 & 1.23 & $0.72-2.10$ & 0.458 & 1.09 & $0.65-1.83$ & 0.740 \\
\hline \multicolumn{2}{|l|}{$\mathrm{SAH}$} & 1.42 & $0.75-2.70$ & 0.288 & 0.72 & $0.43-1.19$ & 0.200 & 0.91 & $0.56-1.47$ & 0.693 \\
\hline \multicolumn{2}{|l|}{ DM } & 0.46 & 0.19-1.07 & 0.071 & 0.90 & $0.51-1.61$ & 0.726 & 1.19 & $0.69-2.05$ & 0.534 \\
\hline \multirow{2}{*}{ Fagerström test } & Very low to medium & 1.00 & - & - & 1.00 & - & - & 1.00 & - & - \\
\hline & High to very high & 2.51 & $1.29-4.91$ & 0.007 & 13.95 & $7.20-27.03$ & $<0.001$ & 6.32 & $3.19-12.50$ & $<0.001$ \\
\hline \multicolumn{2}{|l|}{ Passive smoking } & 0.36 & $0.11-1.21$ & 0.099 & 1,95 & $0.99-3.85$ & 0.055 & 4.26 & $1.88-9.63$ & 0.001 \\
\hline \multirow{3}{*}{ Education } & Middle school & 1.00 & - & - & 1.00 & - & - & 1.00 & - & - \\
\hline & High school & 0.79 & $0.36-1.77$ & 0.570 & 1.03 & $0.55-1.92$ & 0.927 & 1.34 & $0.73-2.45$ & 0.342 \\
\hline & Higher education & 0.16 & $0.02-1.24$ & 0.08 & 0.80 & $0.33-1.94$ & 0.623 & 0.73 & $0.32-1.63$ & 0.438 \\
\hline \multirow{3}{*}{ Average income } & 1-2 minimum wages & 1.00 & - & - & 1.00 & - & - & 1.00 & - & - \\
\hline & 2-3 minimum wages & 0.65 & $0.31-1.38$ & 0.263 & 0.74 & $0.41-1.32$ & 0.302 & 0.72 & $0.42-1.23$ & 0.228 \\
\hline & >3 minimum wages & 0.42 & $0.12-1.46$ & 0.171 & 0.66 & $0.29-1.53$ & 0.332 & 0.77 & $0.36-1.66$ & 0.507 \\
\hline
\end{tabular}

$\mathrm{CABG}=$ coronary artery bypass grafting; $\mathrm{Cl}=$ confidence interval; $\mathrm{DM}=$ diabetes mellitus; $\mathrm{OR}=$ odds ratio; $\mathrm{PCl}=$ percutaneous coronary intervention; $\mathrm{SAH}=$ systemic arterial hypertension

assessed by adding interaction terms to the models. If significant interactions were observed, stratified analyses were performed to better explore each observed interaction.

The present study was approved by the research ethics committee of Fundação São Paulo - PUC-SP Sorocaba campus and the participating patients provided written informed consent. Data were analyzed with IBM SPSS software version 24 (IBM, New York, USA) and GraphPad Prism 5 (GraphPad Software Inc., La Jolla, USA). All tests were two-sided and P-values lower than 0.05 were considered as statistically significant.

\section{RESULTS}

In total, 159 patients who had $\mathrm{PCl}$ and 108 patients who had CABG were included. The characteristics of the patients and the procedures, as well as the variables analyzed in the study, are presented in Table 1. Patients from the $\mathrm{PCl}$ group were significantly older than those from the CABG group (65.5 $\pm 10.1 \mathrm{vs.} 61.8 \pm 8.8)$. The gender distribution was also significantly different between the two groups, with $76.9 \%$ of males in the CABG group and $61.6 \%$ of males in the $\mathrm{PCl}$ group. The prevalence of systemic diseases (systemic arterial hypertension and diabetes mellitus), the level of dependence to nicotine according to the Fagerström score, exposure to passive smoking, education level and monthly income were not significantly different between patients who had CABG or PCl.

The proportion of patients reporting smoking relapse was significantly lower in the CABG than in the PCI group at $30(11.1 \%$ vs. $20.8 \%$ ) and at 180 days (23.1\% vs. $41.5 \%$ ), but no differences were observed between the two groups at 360 days after hospital discharge (Table 2). The occurrence of smoking relapse in patients who had CABG and in those who had PCI was visualized with Kaplan-Meier survival curves (Figure 1). No significant differences on the occurrence of smoking relapse between the two groups was observed with the log-rank test ( $P$-value $=0.238)$. 
Table 4. Multivariate logistic regression model.

\begin{tabular}{|c|c|c|c|c|c|c|c|c|c|c|}
\hline & & \multicolumn{3}{|c|}{30 days } & \multicolumn{3}{|c|}{180 days } & \multicolumn{3}{|c|}{360 days } \\
\hline & & OR & $95 \% \mathrm{Cl}$ & $P$ & OR & $95 \% \mathrm{Cl}$ & $P$ & OR & $95 \% \mathrm{Cl}$ & $P$ \\
\hline \multirow{2}{*}{ Procedure } & $C A B G$ & 1.00 & - & - & 1.00 & - & - & & & \\
\hline & $\mathrm{PCl}$ & 2.15 & $1.00-4.62$ & 0.05 & 2.84 & $1.46-5.51$ & 0.002 & & & \\
\hline \multirow{2}{*}{ Age } & Up to 60 years & 1.00 & - & - & & & & & & \\
\hline & Over 60 years & 7.85 & $2.77-22.21$ & $<0.001$ & & & & & & \\
\hline \multicolumn{2}{|l|}{ DM } & 0.39 & $0.15-1.00$ & 0.05 & & & & & & \\
\hline \multirow{2}{*}{ Fagerström test } & Very low to medium & 1.00 & - & - & 1.00 & - & - & 1.00 & - & - \\
\hline & High to very high & 4.17 & $1.93-9.00$ & $<0.001$ & 15.23 & 7.62-30.43 & $<0.001$ & 7.32 & 3.53-15.18 & $<0.001$ \\
\hline \multicolumn{2}{|l|}{ Passive smoking } & & & & & & & 4.69 & $1.93-11.40$ & 0.001 \\
\hline
\end{tabular}

$\mathrm{CABG}=$ coronary artery bypass grafting; $\mathrm{Cl}=$ confidence interval; $\mathrm{DM}=$ diabetes mellitus; $\mathrm{OR}=$ odds ratio; $\mathrm{PCl}=$ percutaneous coronary intervention

Maintenance of Smoking Cessation

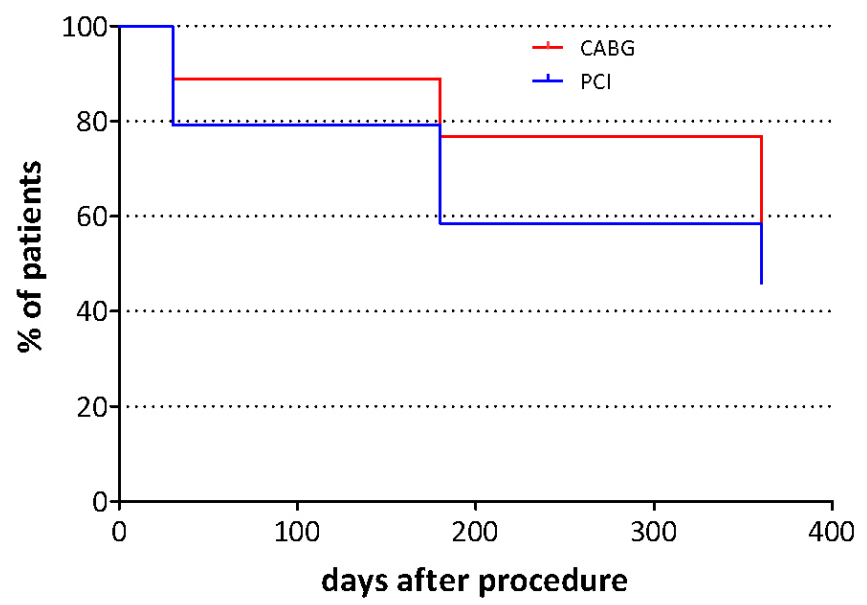

Fig. 1 - Kaplan-Meier curves for the maintenance of smoking cessation (log-rank test, $P=0.238$ ). $C A B G=$ coronary artery bypass grafting; $P C l=$ percutaneous coronary intervention

Univariate logistic regression models indicated that the type of revascularization procedure was significantly associated with smoking relapse at 30 and at 180 days after hospital discharge, with patients from the $\mathrm{PCl}$ group being more likely to relapse smoking than patients from the CABG group (OR: 2.10, 95\% Cl: 1.03-4.27 and OR: 2.36, 95\% Cl: 1.36-4.07, respectively). At 360 days no association between type of revascularization and hospital discharge was observed.

Older age ( $>60$ years old) was associated with a higher rate of smoking relapse 30 days after hospital discharge (OR: 5.66, 95\% Cl: 2.15-14.89), but not at later follow-up assessments. High levels of nicotine dependence assessed by the Fagerström score were associated with the occurrence of smoking relapse at all time points of the study (OR: 2.51, 95\% Cl: 1.29-4.91; OR: $13.95,95 \% \mathrm{Cl}$ : 7.20-27.03 and OR: $6.32,95 \%$ Cl: 3.19-12.50 at 30, 180 and 360 days respectively). Passive smoking was not a significant predictor of smoking relapse at 30 and 180 days, but it was associated to smoking relapse at 360 days after hospital discharge (OR: 4.26, 95\% Cl: 1.88-9.63).

Multivariate logistic regression revealed that the association between type of revascularization procedure (CABG or $\mathrm{PCI})$ and smoking relapse at 30 and 180 days was still observed even when taking possible confounders into account (OR: 2.15, 95\% Cl: 1,004,62 at 30 days and OR: 2.84, 95\% Cl: 1,46-5,51 at 180 days). The association between level of nicotine dependence and smoking relapse also remained significant, at all time points, after taking possible confounders into account (OR: 4.17, 95\% Cl: 1.93-9.00; OR: $15.23,95 \%$ Cl: $7.62-30.43$ and OR: $7.32,95 \%$ Cl: 3.53-15.18 at 30, 180 and 360 days, respectively).

Significant interactions between the type of revascularization procedure and Fagerström score was observed in the multivariate models for 30 and 180 days of follow-up, while in the model for 360 days of follow-up a significant interaction between Fagerström score and passive smoking was observed. In order to better explore these interactions, additional analyses were performed, stratifying the cohort according to the variables between which interaction was observed.

At 30 days of follow-up, the type of intervention was significantly associated with smoking relapse among patients with high Fagerström scores (OR: 6.78, 95\% Cl: 1.52-30.25), but not among those with low Fagerström scores. On the other hand, Fagerström score was associated with smoking relapse among patients with $\mathrm{PCl}$ (OR: 7.16, 95\% Cl: 2.61-19.59), but not among those who had CABG. At 60 days of follow-up, similar results were observed when stratifying patients according to Fagerström score, with type of intervention being associated with smoking relapse only among patients with high Fagerström scores (OR: 9.23, 95\% Cl: 2.53-33.64). When stratifying patients according to type of intervention, however, a significant association between Fagerström score and smoking relapse was observed in both groups (OR: 6.41,95\% Cl: 2,37-17,33 for CABG and OR: 34.23, 95\% Cl: 11.20-104.58 for PCI). At 360 days of follow-up, a correlation between Fagerström score and smoking relapse was only observed among patients not exposed to passive smoking (OR: 8.0, 95\% Cl: 3,67-17,45), while passive smoking was only associated with smoking relapse among patients with low/ 
Table 5. Stratified analysis of the interaction between variables "Procedure" and "Fagerström test" in the relapse of smoking.

\begin{tabular}{|c|c|c|c|c|c|c|}
\hline \multirow{2}{*}{30 days } & & \multicolumn{2}{|c|}{ Fagerström test } & \multirow[b]{2}{*}{ OR } & \multirow[b]{2}{*}{$95 \% \mathrm{Cl}$} & \multirow[b]{2}{*}{$P$} \\
\hline & & Very low to medium & High to very high & & & \\
\hline \multirow{5}{*}{ Procedure } & CABG & 9/83 (10.8\%) & $3 / 25(12 \%)$ & 1.36 & $0.31-6.00$ & 0.683 \\
\hline & $\mathrm{PCl}$ & $17 / 115(14.8 \%)$ & $16 / 44(36.4 \%)$ & 7.16 & $2.61-19.59$ & $<0.001$ \\
\hline & OR & 1.16 & 6.78 & & & \\
\hline & $95 \% \mathrm{Cl}$ & $0.47-2.86$ & $1.52-30.25$ & & & \\
\hline & $P$ & 0.749 & 0.012 & & & \\
\hline \multirow{2}{*}{\multicolumn{2}{|c|}{180 days }} & \multicolumn{2}{|c|}{ Fagerström test } & & & \\
\hline & & Very low to medium & High to very high & OR & $95 \% \mathrm{Cl}$ & $P$ \\
\hline \multirow{5}{*}{ Procedure } & CABG & $12 / 83(14.5 \%)$ & $13 / 25(52 \%)$ & 6.41 & $2.37-17.33$ & $<0.001$ \\
\hline & $\mathrm{PCl}$ & 23/115 (22.6\%) & 40/44 (90.9\%) & 34.23 & $11.20-104.58$ & $<0.001$ \\
\hline & OR & 1.73 & 9.23 & & & \\
\hline & $95 \% \mathrm{Cl}$ & $0.82-3.67$ & $2.53-33.64$ & & & \\
\hline & $P$ & 0.154 & 0.001 & & & \\
\hline
\end{tabular}

$\mathrm{CABG}=$ coronary artery bypass grafting; $\mathrm{Cl}=$ confidence interval; $\mathrm{OR}=$ odds ratio; $\mathrm{PCl}=$ percutaneous coronary intervention

Table 6. Stratified analysis of the interaction between variables "Passive smoking" and "Fagerström test" in the relapse of smoking.

\begin{tabular}{l|l|c|c|c|c|c}
\hline \multirow{2}{*}{360 days } & \multicolumn{2}{|c|}{ Fagerström test } & OR & $\mathbf{9 5 \% ~ C l}$ & \multicolumn{1}{c}{$\boldsymbol{P}$} \\
\cline { 3 - 7 } & & Very low to medium & High to very high & 8.00 & $3.67-17.45$ & $<0.001$ \\
\hline \multirow{2}{*}{ Passive smoking } & no & $66 / 174(37.9 \%)$ & $44 / 53(83 \%)$ & 1.14 & $0.23-5.62$ & 0.872 \\
\cline { 2 - 7 } & yes & $19 / 24(79.2 \%)$ & $13 / 16(81.3 \%)$ & & \\
\hline & OR & 6.2 & 0.89 & & \\
\hline & $95 \% \mathrm{Cl}$ & $2.22-17.45$ & $0.21-3.76$ & & \\
\hline
\end{tabular}

$\mathrm{Cl}=$ confidence interval; OR=odds ratio

moderate dependence to nicotine according to Fagerström test (Tables 5 and 6).

\section{DISCUSSION}

The present study addressed the hypothesis that there is a strong association between a major event in the patient's health and a radical change in habit, in this case smoking. We investigated the rate and perpetuation of smoking cessation after two different myocardial revascularization methods: CABG and $\mathrm{PCl}$. Our results showed that the number of patients reporting smoking relapse was significantly lower in the CABG than in the $\mathrm{PCl}$ group up to 180 days of follow-up, but no differences were observed at 360 days after hospital discharge. Furthermore, although CABG represented a factor for smoking cessation in the short-term, high levels of nicotine dependence and passive smoking showed to be important predictors of smoking relapse in the long-term.
This study also showed an interaction between the myocardial revascularization method and the Fagerström score, in such a way that in patients with low levels of nicotine dependence, the procedure of choice has no significant impact on smoking cessation. This might be related to the fact that, in this group, most patients cease smoking regardless of the revascularization method, while in the group of patients with high levels of nicotine dependence mostly those undergoing CABG cease smoking and the ones subjected to $\mathrm{PCl}$ continue or relapse smoking.

Another interesting interaction found in the present study was between the Fagerström score and passive smoking. Our results suggest that in patients with low levels of nicotine dependence, passive smoking is related to a higher rate of relapse, while in patients with high levels of nicotine dependence passive smoking does not affect the maintenance of smoking cessation. For these patients, the rate of relapse is high regardless of the presence of a family member who also smokes, while for 
those, mostly the ones exposed to passive smoking will relapse smoking.

One limitation of the current study was that patients indicated to different revascularization procedures may also present different symptomatology, which could differently impact their predisposition to quit smoking and maintain smoking cessation. Future studies should take this variable into consideration. On the other hand, some of the strengths of the present study were its prospective nature and the long follow-up period. These two characteristics increase the reliability and validity of our findings.

Association between the procedure invasiveness and smoking cessation was also observed in another study with patients treated for coronary artery disease, in which a higher rate of smoking cessation was observed after surgical revascularization (55\%) than after percutaneous intervention (25\%) or angiography alone (14\%) one year after the procedure ${ }^{[7]}$. A second study revealed comparable high rates of smoking cessation following surgical revascularization both at 60 days (93.15\%) and 90 days (93.84\%) after the procedure ${ }^{[6]}$. However, the proportion of patients who relapse 12 months after quitting smoking was similar in the percutaneous (53.4\%) and surgical $(52.7 \%)$ groups $^{[6]}$. Several investigations through the past 15 years reported similar abstinence rates, with approximately $40 \%$ of smoking cessation maintenance at 12 months after myocardial infarction followed by elective surgical revascularization and $55.4 \%$ after percutaneous coronary intervention ${ }^{[8,9]}$.

Although patients submitted to major surgeries present a higher probability of succeeding on smoking cessation in the short-term, when compared to those undergoing a procedure in an outpatient setting, both this study and the literature show that this difference does not remain over time. An interesting alternative to potentiate the beneficial psychological effects of a major surgical procedure is the combination with counseling during hospitalization or at the time of surgical intervention, what was previously described as a teaching moment ${ }^{[10]}$. This way, an early intervention during hospital stay, could present a high possibility of success in smoking cessation ${ }^{[11]}$. Furthermore, if counseling is possible to be started a reasonable time before the intervention, it is also associated with lower rates of postoperative complications, as observed in a meta-analysis that revealed a $40 \%$ reduction in the relative risk of total complications with preoperative smoking cessation ${ }^{[7,10,12-14]}$

Cigarette smoking represents a complex problem with significant implications for cardiovascular diseases and, although the prevalence of smoking decreased in the past 45 years, smoking cessation rates (defined as 6 months of tobacco abstinence) has been estimated at only $6 \%$ in recent years ${ }^{[15]}$.Cigarette smoking contributes to cardiovascular diseases in several ways. The toxic products of cigarette circulate in the bloodstream, increasing the inflammatory response and interfering with the function of the endothelium and causing abnormalities that lead to the development of atherosclerotic lesions on the arterial wall. This leads to the narrowing of blood vessels, gradually impairing blood flow, as well as makes the arteries stiffer, less elastic and prone to rupture ${ }^{[16]}$. Over time, it is possible to observe a progressively impaired vasomotor reactivity in smokers, as well as platelet dysfunction. Previous studies have described the correlation between smoking and increased levels of C-reactive protein (CRP), fibrinogen and homocysteine. Furthermore, smoking increases the inflammatory response, which in association with higher levels of homocysteine can represent an important mechanism of atherosclerosis development ${ }^{[17]}$.

Smoking cessation can reduce the progression of arterial disease, the risk of myocardial infarction, and the mortality due to cardiovascular diseases in more than one third, surpassing other preventive treatments ${ }^{[9]}$. When smokers are hospitalized they can be more prone to accept interventions for smoking cessation ${ }^{[10]}$, but individual characteristics, such as level of addiction to nicotine and contact with other smokers, are potential factors of failure ${ }^{[18]}$. Still, smoking cessation programs should be strongly encouraged for patients undergoing surgical procedures ${ }^{[19]}$.

\section{CONCLUSION}

The present study showed that, in the short-term, the number of patients reporting smoking relapse was significantly lower among those undergoing CABG than in the group subjected to $\mathrm{PCl}$ in the short-term. However, in the long-term, this difference did not remain. High levels of nicotine dependence and passive smoking showed to be important predictors of smoking relapse. Still, the occurrence of a major surgical procedure seems to be a special setting for smoking cessation guidance to have higher chances of success. Further studies, combining counseling with the surgical intervention, should be performed to evaluate this scenario.

\section{Authors' roles \& responsibilities}

RN Conception of the work; acquisition, analysis and interpretation of data for the work; revising; final approval of the manuscript version to be published

GKA Conception and design of the work; manuscript redaction or critical review of its content; final approval of the manuscript version to be published

FBO Acquisition and analysis of data; final approval of the manuscript version to be published

JAFS Acquisition and analysis of data; final approval of the manuscript version to be published

\section{REFERENCES}

1. Cooke JP, Bitterman H. Nicotine and angiogenesis: a new paradigm for tobacco-related diseases. Ann Med. 2004;36(1):33-40.

2. Instituto Nacional do Cancer. Programa Nacional de Controle do Tabagismo. Available_from:_http://www2.inca.gov.br/ps/wcm/ connect/acoes_programas/site/home/nobrasil/programa-nacionalcontrole-tabagismo/tabagismo

3. Araújo AJ, Menezes AMB, Dórea AJPS, Torres BS, Viegas CAA, Silva CAR, et al. Diretrizes para cessação do tabagismo. J Bras Pneumol. 2004;30(Suppl 2):S1-76.

4. Critchley JA, Capewell S. Mortality risk reduction associated with smoking cessation in patients with coronary heart disease: a systematic review. JAMA [online]. 2003;290(1):86-97. 
5. Barth J, Critchley J, Bengel J. Efficacy of psychosocial interventions for smoking cessation in patients with coronary heart disease: a systematic review and meta-analysis. Ann Behav Med. 2006;32(1):10-20.

6. Pietrobon RC, Barbisan JN. Impact of coronary artery bypass graft surgery in smoking cessation. Rev Bras Cir Cardiovasc. 2010;25(1):79-84.

7. Rallidis LS, Lekakis J, Panagiotakos D, Fountoulaki K, Komporozos C, Apostolou T, et al. Long-term prognostic factors of young patients ( $\leq 35$ years) having acute myocardial infarction: the detrimental role of continuation of smoking. Eur J Cardiovasc Prev Rehabil. 2008;15(5):567-71.

8. Saksens NT, Noyez L. Smoking behaviour and attitudes in patients undergoing cardiac surgery. The Radboud experience. Interact Cardiovasc Thorac Surg. 2010;10(2):195-9.

9. Hammal F, Ezekowitz JA, Norris CM, Wild TC, Finegan BA; APPROACH Investigators, Smoking status and survival: impact on mortality of continuing to smoke one year after the angiographic diagnosis of coronary artery disease, a prospective cohort study. BMC Cardiovasc Disord.. 2014;14:133.

10. Pereira TV, Rudnicki M, Franco RF, Pereira AC, Krieger JE. Effect of the G-308A polymorphism of the tumor necrosis factor al pha gene on the risk of ischemic heart disease and ischemic stroke: a meta-analysis. Am Heart J. 2007;153(5):821-30.

11. Moghbeli N, Kirtane AJ, Ray KK, Murphy SA, Gibson CM, Braunwald E, et al. C-reactive protein and cardiovascular outcomes in smokers versus nonsmokers in non-ST-elevation acute coronary syndrome (from the TACTICS-TIMI 18 trial). Am J Cardiol. 2005;96(5):635-8.

12. Guilbert JJ. The world health report 2002 - reducing risks, promoting healthy life. Educ Health. 2003;16(2):230.

13. Azevedo e Silva G, Valente JG, Malta DC. Trends in smoking among the adult population in Brazilian capitals: a data analysis of telephone surveys from 2006 to 2009. Rev Bras Epidemiol. 2011;14(Suppl 1):103-14.

14. Sepehripour AH, LoTT, McCormack DJ, Shipolini AR. Is there benefit in smoking cessation prior to cardiac surgery? Interact Cardiovasc Thorac Surg. 2012;15(4):726-32.

15. Centers for Disease Control and Prevention (CDC). Quitting smoking among adults: United States, 2001-2010. MMWR Morb Mortal Wkly Rep. 2011;60(44):1513-9.

16. Khullar D, Maa J. The impact of smoking on surgical outcomes. J Am Coll Surg. 2012;215(3):418-26.

17. Bazzano LA, He J, Muntner P, Vupputuri S, Whelton PK. Relationship between cigarette smoking and novel risk factors for cardiovascular disease in the United States. Ann Intern Med. 2003;138(11):891-7.

18. Levitzky YS, Guo C-Y, Rong J, Larson MG, Walter RE, Keaney JF Jr, et al. Relation of smoking status to a panel of inflammatory markers: The Framingham offspring. Atherosclerosis. 2008;201(1):217-24.

19. Yanbaeva DG, Dentener MA, Creutzberg EC, Wesseling G, Wouters EF. Systemic effects of smoking. Chest. 2007;131(5):1557-66. 